\title{
Chemical variation in the ventral hippocampus and other brain sites during conditioned avoidance'
}

\author{
JOHN GAITO, JAMES MOTTIN, and JAMES H. DAVISON, \\ York University and Waterloo University, Toronto, Ontario, \\ Canada
}

No differences between learning and nonlearning rats were found in neurochemical measures in the ventral hippocampus but differences were present in the medial ventral cortex.

In previous experiments (Gaito, Mottin, \& Davison, in press), chemical measures of the medial ventral cortex (MV) differentiated between learning and nonlearning animals. The separation of ventral cortex from underlying white matter is difficult, and ventral cortices tend to contain some subcortical tissue. Therefore, the significant results in MV might be due to the sole contribution of portions of the hippocampus. Since the hippocampus had been implicated in learning events (e.g., see Adey et al, 1960; Gaito, 1966), it is reasonable to hypothesize that the significant differences in MV were due to hippocampal function. Two replicated experiments were conducted to evaluate this hypothesis.

\section{METHOD}

In the two experiments, the task was one-way active avoidance conditioning with the shock level set at $1.5 \mathrm{~mA}$. Eight pairs of littermates were used in each experiment; their ages varied from 69 to 80 days; all but two litters were males (Wistar strain).

In both experiments there were two groups of rats: Shock Avoidance, E (given 15 trials in $15 \mathrm{~min}$ ), and Controls, $\mathrm{C}$ (in the shock chamber for $15 \mathrm{~min}$ without any treatment). All rats were allowed a 15-min adaptation period in the shock chamber.

At the end of the 30-min period in the apparatus each rat was sacrificed by immersion in liquid nitrogen for $10 \mathrm{sec}$. The brain was rapidly removed and sectioned into the ventral hippocampus (VH) and 10 sites as in previous experiments (Gaito, Mottin, \& Davison, in press): anterior ventral cortex (AV), medial ventral cortex (MV), posterior ventral cortex (PV), anterior dorsal cortex (AD), medial dorsal cortex (MD), posterior dorsal cortex (PD), cerebral hemispheres $(\mathrm{CH})$, cerebellum (CB), upper brain stem (UBS), and lower brain stem (LBS) (sectioned just below the inferior colliculi). RNA, DNA, and proteins were extracted by a modified SchmidtTannhauser procedure and the amounts of each were determined by spectrophotometric analysis.

One half hour before being placed in the apparatus each rat was injected intracranially with $5 \mu \mathrm{c}$ of valine- $\mathrm{C}^{14}$ (specific activity $-117 \mathrm{mc} / \mathrm{mM}$ ) to determine incorporation rates into protein.

The dependent variables in Experiments 1 and 2 were: RNA, DNA, and protein (all per gram of tissue, wet weight), RNA/DNA, prot/DNA, prot/RNA, and relative specific activity of the protein fraction (R.S.A. Prot), i.e., specific activity of the protein fraction (S.A. Prot)/specific activity of the cell pool fraction (S.A. Cell Pool). Littermates by Conditions analyses of variance were conducted with the rejection region set at a $p$ of .10 so as to decrease the $p$ of Type $\mathrm{H}$ errors. Because Type I errors increase as a result of this aspect, only tissues which showed significant results in two or more chemical measures and/or experiments were considered real ones.

RESULTS AND DISCUSSION

In both experiments E's showed six or more avoidance responses in 15 trials. The tissues with more than one significant result at $p \leqslant .10$ are presented in Table 1.2

Although MV again showed differences, no significant differences appeared in VH in either experiment. In both experiments $\mathrm{E}$ rats had significantly greater $\mathrm{MV}$ means than $\mathrm{C}$ animals in R.S.A. Prot. In Experiment 1, E $>\mathrm{C}$ also in protein/DNA. These results suggest a greater relative turnover in proteins for learning animals. Thus the present results do not allow the acceptance of the hypothesis that significant differences in MV in previous experiments were due solely to hippocampal function.

In both experiments there were significant differences in tissues which are concerned with motor functions, $A D$ and $C B$. In the previous experiments, $C B$ consistently indicated differences between $\mathrm{E}$ and $\mathrm{C}$ also. The results with both tissues probably are related to the motor activity during the task.

In both experiments there was a tendency for the means of $E$ to be greater than those for $C$ over the 11 tissues for R.S.A. Prot and for S.A. Cell Pool. These results indicated that the E animals had a greater amount of label in the cell pool and protein fractions over the whole brain than did the $\mathrm{C}$ rats.

In these two experiments there was a tendency for $\mathrm{E}>\mathrm{C}$ in tissues, whereas in previous experiments $\mathrm{E}<\mathrm{C}$ (Gaito. Mottin, \& Davison, in press). The basis for this discrepancy is probably the differences in shock levels used. Because RNA and protein changes during stimulation appeared to be transient ones, the shock level was set at $2.5 \mathrm{~mA}$ so as to provide avoidance learning within $15 \mathrm{~min}$. With this high shock level quick learning was effected. For the present experiments the shock level was reduced to $1.5 \mathrm{~mA}$ and quick learning was achieved also. This decreased shock level appeared to increase protein synthesis and protein ratios whereas the higher shock level had the reverse effect. The present results are consistent with those by Zemp et al (1966) who reported increased incorporation of radioactive uridine into brain RNA during shock avoidance conditioning with low shock levels. Furthermore, there are data which indicate that mild stimulation results in increased RNA and protein synthesis and amounts whereas drastic stimulation effects a decrease (Gaito, 1966).

From these experiments one would conclude that there is again the suggestion that MV may be involved in shock avoidance conditioning. The lack of significant differences between $\mathrm{E}$ and $\mathrm{C}$ in $\mathrm{VH}$ (along with differences in MV) suggests that the differences previously observed in MV are not due to the contribution of this portion of the hippocampus. Such results do not exclude the hippocampus from involvement in this type of avoidance task, however. The hippocampus may activate other tissues such as MV. This function may be a fleeting one and any neurochemical changes effected might be obscured at 10 to $15 \mathrm{~min}$ after this "triggering" effect when evaluated by our methods. This

Table 1

Significant Results in Various Tissues

Tissues

MV AD

CB

Exp. 1 Prot/DNA $(E>C) \quad$ Prot/DNA $(E<C)$ R.S.A.Prot $(E>C)$ Prot $/$ RNA $(E<C)$ R.S.A.Prot $(E<C)$

R.S.A. Prot $(E>C)$

Prot/RNA $(E<C)$

Prot/DNA $(\mathrm{E}<\mathrm{C})$ R.S.A. Prot $(E>C)$ 
possibility was suggested by the results of Adey, Dunlop, \& Hendrix (1960).

In these and previous learning experiments, the consistent significance of $\mathrm{MV}$ could indicate changes due to learning, an interpretation which is suggested by results of other investigators (Gaito, 1966). However, the differences noted in these sites could be due to the stressing agent involved (electric shock). Research with other learning tasks and lesion studies are underway to determine whether the differences reflect neurochemical events unique to learning or to other processes such as stress.

\section{REFERENCES}

ADEY, W. R., DUNLOP, C. W., \& HENDRIX, E. E. Hippocampal slow waves. American Medical Association Archives on Neurology, 1960, 3 , 74-90.
GAITO, J. Molecular psychobiology. Springfield, Ill.: C. C. Thomas, 1966

GAITO, J., MOTTIN, J., \& DAVISON, J. H. Chemical variation in brain loci during shock avoidance. Psychonomic Science, in press.

ZEMP, J. W., WILSON, J. E., SCHLESINGER, K., BOGGAN, W. O., \& GLASSMAN, E. Brain function and macromolecules. I. Incorporation of uridine into RNA of mouse brain during short-term training experience. Proceedings of the National Academy of Science, 1966, $55,1423-1431$.

NOTES

1. This work was supported by Office of Naval Research Contract Nonr-4935(00) and grants from the National Research Council of Canada.

2. Complete data may be obtained by writing the first author. 